\title{
Characteristics, Detection Methods and Treatment of Questionable Occlusal Carious Lesions: Findings from The National Dental Practice-Based Research Network
}

\author{
S.K. Makhija ${ }^{a} \quad$ G.H. Gilbert ${ }^{a} \quad$ E. Funkhouser ${ }^{b} \quad$ J.D. Bader ${ }^{c} \quad$ V.V. Gordan ${ }^{d} \quad$ D.B. Rindal ${ }^{e}$ \\ D.J. Pihlstrom ${ }^{f}$ V. Qvist ${ }^{g}$ for The National Dental PBRN Collaborative Group
}

a Department of Clinical and Community Sciences, School of Dentistry, University of Alabama at Birmingham and

${ }^{b}$ Division of Preventive Medicine, Department of Medicine, University of Alabama at Birmingham, Birmingham, Ala., 'Department of Operative Dentistry, University of North Carolina at Chapel Hill, Chapel Hill, N.C., ${ }^{\text {d Department of }}$ Restorative Dental Sciences, Division of Operative Dentistry, College of Dentistry, University of Florida Health Science Center, Gainesville, Fla., ${ }^{e}$ HealthPartners Institute for Education and Research, Minneapolis, Minn., and ${ }^{\mathrm{f}}$ Permanente Dental Associates, Portland, Oreg., USA; ${ }^{9}$ Department of Cariology and Endodontics, School of Dentistry, University of Copenhagen, Copenhagen, Denmark

\section{Key Words}

Clinical research · Dental caries · Multicenter studies ·

Practice-based research · Questionable lesions

\begin{abstract}
Questionable occlusal carious lesions (QOC) can be defined as an occlusal tooth surface with no cavitation and no radiographic radiolucencies, but caries is suspected due to roughness, surface opacities or staining. An earlier analysis of data from this study indicates $1 / 3$ of patients have a QOC. The objective of this report has been to quantify the characteristics of these common lesions, the diagnostic aids used and the treatment of QOC. A total of 82 dentist and hygienist practitioner-investigators from the USA and Denmark in the National Dental Practice-Based Research Network participated. When consenting patients presented with a QOC, information was recorded about the patient, tooth, lesion and treatments. A total of 2,603 QOC from 1,732 patients were analyzed. The lesions were usually associated with a fissure,
\end{abstract}

on molars, and varied from yellow to black in color. Half presented with a chalky luster and had a rough surface when examined with an explorer. There was an association between color and luster: $10 \%$ were chalky-light, $47 \%$ were shiny-dark and $42 \%$ were mixtures. A higher proportion of chalky than of shiny lesions were light ( $22 \mathrm{vs.} 9 \%$; $p<0.001$ ). Lesions light in color were less common in adults than in pediatric patients ( 9 vs. $32 \% ; p<0.001$ ). Lesions that were chalky and light were more common among pediatric than among adult patients ( 22 vs. $6 \% ; p<0.001$ ). This is the first study to investigate characteristics of $\mathrm{QOC}$ in routine clinical practice. Clinicians commonly face this diagnostic uncertainty. Determining the characteristics of these lesions is relevant when making diagnostic and treatment decisions.

(C) 2014 S. Karger AG, Basel

The National Dental PBRN Collaborative Group comprises practitioner-investigators, faculty investigators and staff members who contributed to this activity. A list of these persons is at http://www. nationaldentalpbrn.org/collaborative-group.php.

\section{KARGER}

E-Mail karger@karger.com

www.karger.com/cre (c) 2014 S. Karger AG, Basel

$0008-6568 / 14 / 0483-0200 \$ 39.50 / 0$
Dr. Sonia K. Makhija, Assoc. Prof.

Department of Clinical and Community Sciences

UAB School of Dentistry, 1919 7th Avenue South, SDB 111

Birmingham, AL 35294-0007 (USA)

E-Mail smakhija@uab.edu 
Despite considerable improvements in oral health [Brown et al., 2000], dental caries remains a significant health problem [NHANES III, 1996] that is experienced by more than $90 \%$ of all United States dentate adults and more than $2 / 3$ of all children, with a wide range of severity [Kaste et al., 1996; Winn et al., 1996]. With the advent of fluoride [Lussi, 1993; Basting and Serra, 1999; White and Eakle, 2000; Pitts, 2004] the incidence of caries in the overall population has lessened in recent years. The effects of fluoride, though, have led to difficulty in detecting carious lesions on the occlusal surface because fluoride can result in an intact surface with subsurface demineralization [Lussi, 1993; Hamilton et al., 2001], which can lead to changes in the physical appearance of these carious lesions [Pine and Bosch, 1996]. There are essentially two types of such lesions. In 'hidden caries', demineralization has progressed to the point where it is detectable radiographically. In 'questionable occlusal carious lesions (QOC)', which are the focus of this study, the tooth has no cavitation and no radiographic evidence of caries, but the presence of a carious lesion is suspected due to roughness, surface opacities or staining. Such QOC lesions may be difficult to detect [Sawle and Andlaw, 1988; Ketley and Holt, 1993; Pine and Bosch, 1996; Pitts, 1997; Ouellet et al., 2002].

Questionable lesions present practitioners with a difficult diagnostic decision [Lussi, 1993; Kidd et al., 1993; Pine and Bosch, 1996; Weerheijm, 1990]. To date there have been very few studies regarding the characteristics, management and treatment of these lesions [Meiers and Jensen, 1984; Sawle and Andlaw, 1988; Ketley and Holt, 1993; Hamilton et al., 2001; Ouellet et al., 2002], and only one examining their progression [Hamilton et al., 2002]. As a result there is no consensus on their management. However, the relatively slow progression of occlusal carious lesions in general [Ketley and Holt, 1993; Balevi, 2008], coupled with the possibility of their arrest or reversal, and the success of sealants and fluoride in stopping the progression of frank dentinal carious lesions (caries that is clearly in the dentin, either seen clinically or radiographically), all argue for a conservative approach [Groeneveld et al., 1990; Bader and Shugars, 2006; Frencken et al., 2012]. Ismail et al. [2001] found that although general dentists spend a bulk of their time restoring lesions, there is a growing interest in the preventive aspects of managing these lesions. If more evidence is gathered regarding the characteristics of these lesions as well as the treatment outcomes, dentists will be able to help their patients manage their oral health by nonsurgical means, which can lead to an impact on daily clinical practice [Kidd and Nyvad, 2003].

National Dental PBRN Study of QOC
Given the scarcity of well-conducted studies that support this recommendation about clinical management, it is clear that more needs to be known about the epidemiology of QOC. An earlier analysis of data from this study indicates that among patients attending dental practices affiliated with the National Dental Practice-Based Research Network (PBRN), an overall patient prevalence of $34 \%$ was observed [Makhija et al., 2012]. Because of this relatively high prevalence, clinicians may benefit from a careful description of the characteristics of these lesions. The purpose of this study was to determine the characteristics of these lesions, the diagnostic aids used and the treatment of these lesions found in general and pediatric practice settings.

\section{Material and Methods}

\section{The National Dental PBRN}

We conducted this study on patients visiting dental practices affiliated with the National Dental PBRN. The network is a consortium of dental practices, established to answer questions raised by dental practitioners in everyday clinical practice and to evaluate the effectiveness of strategies to prevent, manage and treat oral diseases and conditions [Gilbert et al., 2008; Makhija et al., 2009]. The network includes dental health care personnel (general dentists, dental specialists and hygienists). At the time of this study, the network mainly comprised 5 geographic regions:

- Alabama/Mississippi (AL/MS);

- Florida/Georgia (FL/GA);

- Minnesota (MN), encompassing dentists either employed by HealthPartners (Minnesota) or in private practice;

- Permanente Dental Associates (PDA), in cooperation with Kaiser Permanente's Center for Health Research (Oregon and Washington); and

- Scandinavia, encompassing Denmark (DK), Norway and Sweden, although in this study only Denmark participated.

The network represents dentists and hygienists who are diverse with regard to practice type (solo and small group practice, large group practice, public health practice), treatment philosophy, race, ethnicity, workload, age and sex. The AL/MS and FL/GA regions mainly comprised solo and small group practices (3 dentists or fewer). The MN region mainly comprised solo and large group practices (4 dentists or more). The DK region comprised dentists and hygienists in small and solo group practices as well as public health practices.

Although the network dentists have substantial diversity, previous analyses have documented that network dentists have much in common with dentists at large [Makhija et al., 2009]. At the time of this study, more than 1,000 practitioners, including 68 hygienists, were enrolled in the network. Specifics regarding network practitioners have been reported previously [Makhija et al., 2009].

Selection and Recruitment Process

Network practitioners were recruited by regional coordinators through continuing dental education courses sponsored by the network, as well as via letters sent to licensed practitioners from the participating regions. To be eligible for this study, practitio- 
ners had to complete both the enrollment questionnaire and a questionnaire regarding how they diagnose and treat dental caries (Assessment of Caries Diagnosis and Caries Treatment questionnaire; http://nationaldentalpbrn.org/study-results.php), attend an orientation session or watch a video of it, and complete their training in human subject protection. To become a member of the network, practitioners must first complete an enrollment questionnaire. This questionnaire, which is publicly available at http://nationaldentalpbrn.org/enrollment.php, collects information about practitioner, practice and patient characteristics.

\section{Study Design}

The data were collected by network dentists and hygienists (practitioners) in their offices. As previously reported [Makhija et al., 2012], participating practices maintained a consecutive patient log of patients presenting with unrestored occlusal surfaces for approximately 100 patients. If a patient presented with a QOC, met the requirement of having a radiograph no older than 6 months, and consented to participate in the study, the practitioner filled out a data collection form (up to 2 lesions could be enrolled per patient). The data collection form included specific information about the patient and lesion. Practices were asked to enroll approximately 25 lesions. Copies of the data collection forms are available at http://nationaldentalpbrn.org/study-results.php.

After the offices completed the initial data collection phase of the study, radiographs for 5 randomly selected patients with digital radiographs were chosen for each office and sent to an independent reviewer (to alleviate any concerns about conflicts of interest), so verification could be provided that no occlusal carious lesions were present. If the presence of a radiolucency indicated a carious lesion within the occlusal enamel or within underlying dentin, the lesion would not have been enrolled. During the review process, however, no radiographs from any office were deemed to have disclosed radiographic evidence of occlusal carious lesions.

\section{Statistical Methods}

The (1) practitioners/practices and patient characteristics, (2) lesion characteristics, (3) diagnostic aids used, (4) treatments, (5) clinical findings and (6) materials used in case of invasive treatments are described overall and by region (tables $1-3) \cdot \chi^{2}$ tests were used for initial assessments of the significance of differences in these variables across regions. Generalized linear models were used to adjust statistical significance for clustering within practices. The following outcomes were determined: (1) associations between characteristics and methods of diagnosis, and (2) association of methods of diagnosis with treatment.

Separate models were run for each diagnostic aid assessed (outcome), i.e. dental explorer, air drying, magnification and radiographs. Primary analysis regarding treatment was whether or not treatment was invasive. For these analyses, enameloplasty, preventive resin restoration and full restoration were combined and classified as 'invasive' (tooth structure was removed). Associations with full restorations (lesions treated by enameloplasty or preventive resin restoration were excluded) were also assessed, and associations with enameloplasty, excluding lesions treated with preventive resin or full restorations.

For each analysis, a full model and a reduced model were fit. Full models assessing associations with diagnostic aids included: region; whether or not the patient was pediatric (age $\leq 18$ years); tooth type (molar/premolar); lesion luster; and color. For associa- tions with treatments, diagnostic aids used were also included. Practice and practitioner characteristics were assessed, but after accounting for clustering within practice, most models would not run (insufficient cluster size, variation within clusters); exceptions are noted. Backward elimination was used to fit reduced models; namely, variables were removed one at a time, leaving only variables with $\mathrm{p}<0.05$ in the model. Odds ratios (OR) and $95 \%$ confidence intervals (CI) were calculated from the models. All analyses were performed with $\mathrm{SAS}^{\circledR}$ version 9.1.

A total of 2,670 lesions (1,765 patients) were enrolled in the study. A total of 67 lesions (33 patients) were excluded due to missing data on: patient age $(\mathrm{n}=1)$; luster $(\mathrm{n}=11)$; color $(\mathrm{n}=34)$; color classified as 'other' $(\mathrm{n}=24)$; and no indication of treatment options $(n=9)$. This left 2,603 lesions ( 1,732 patients) for analysis. A higher proportion of lesions from Southeast USA (AL/MS and FL/GA) than from elsewhere were excluded $[5 \%(54 / 1,154)$ vs. $1 \%$ $(13 / 1,516) ; \mathrm{p}<0.001]$ and had received invasive treatment $[8 \%$ $(30 / 379)$ vs. $1.6 \%(37 / 2,291) ; \mathrm{p}<0.001]$.

The respective institutional review boards in each region approved the study and all patients provided informed consent after dentists or their staff provided them with a full explanation of the nature of the procedures. The informed consent of all human subjects who participated in this investigation was obtained after the nature of the procedures had been fully explained.

\section{Results}

\section{Practices/Practitioners and Patients}

A total of 70 dentists from the USA and DK and 12 Danish dental hygienists collected the data (table 1). Of the 82 participating practices, 13 were pediatric practices, 34 practitioners were female, 69 were non-Hispanic white, and 27 had graduated 1990 or later. The mean numbers of patients and lesions enrolled per practice were 21 and 32, respectively. All of these characteristics differed by region, notably the proportion of pediatric practices (30-33\% for $\mathrm{AL} / \mathrm{MS}$ and $\mathrm{DK}$, none in $\mathrm{MN}$, and only $1,<7 \%$, in the other 2 regions), and the PDA region enrolled fewer patients and lesions per practice than did the other regions.

The mean age $( \pm \mathrm{SD})$ of patients was $33 \pm 18$ years (range: $5-92$ years) and $27 \%$ were pediatric ( $\leq 18$ years old). Overall, $47 \%$ were male, $70 \%$ were white, and $90 \%$ had some form of dental insurance. These values did not differ across regions after adjusting for clustering within practices.

\section{Lesions/Tooth}

Overall, 69\% of the lesions involved molars, 52\% were on mandibular teeth, $49 \%$ presented with a chalky luster, $15 \%$ were light (yellow or light brown) in color, and 455 had a rough texture (table 2 ). There was an association between color and luster, with a higher proportion of chalky than shiny lesions that were light $[22 \%(274 / 1,266)$ vs. $9 \%(115 / 1,337)$; adjusted for clustering $\mathrm{OR}=2.2(95 \%$ 
Table 1. Practice/practitioner and patient characteristics by region*

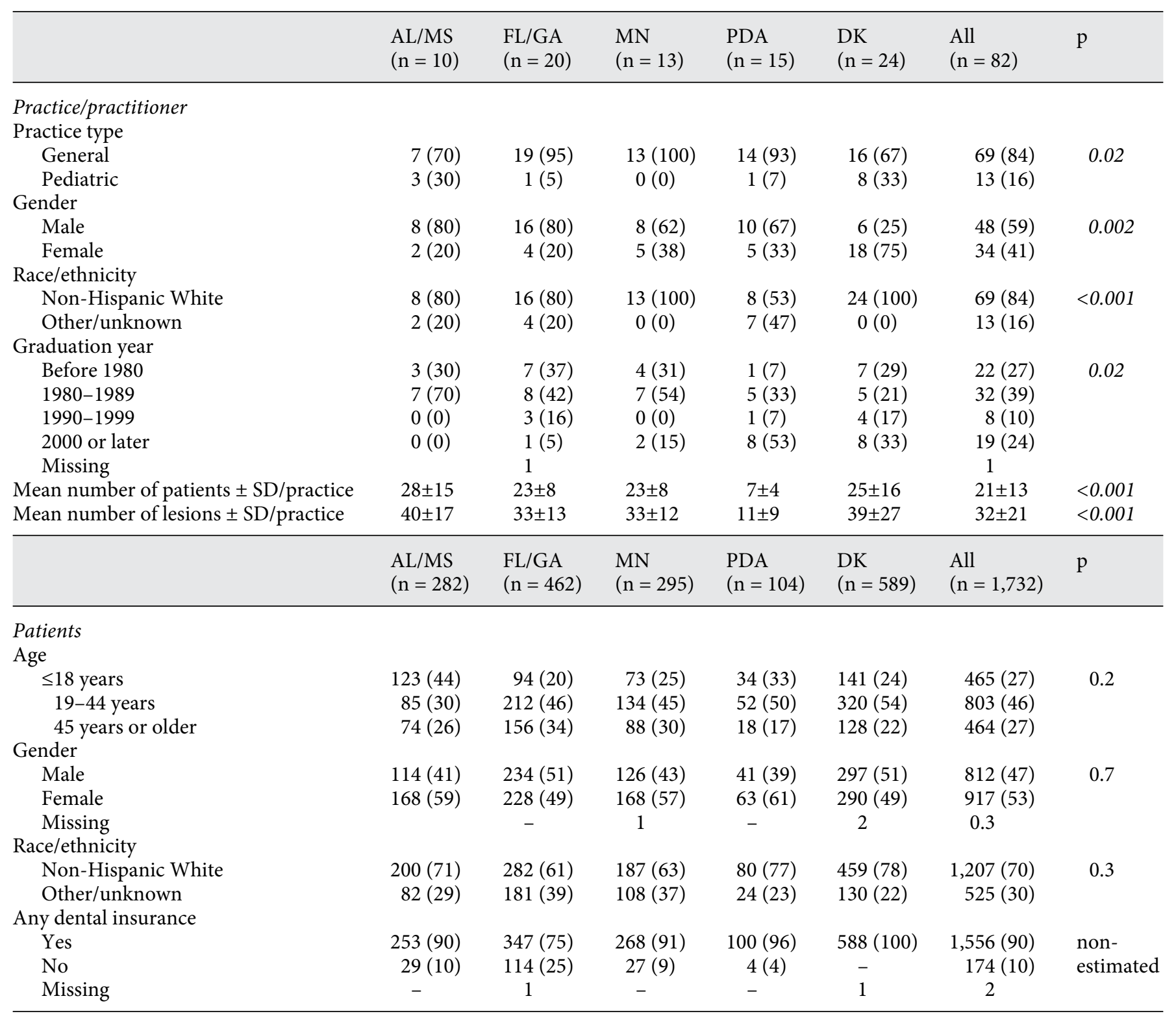

Values in parentheses denote percentages unless specified otherwise. ${ }^{*}$ At the time of the study, the National Dental PBRN mainly comprised these 5 geographic regions. AL/MS = Alabama/Mississippi; FL/GA = Florida/Georgia; $\mathrm{MN}=\mathrm{Minnesota}$; PDA = Permanente Dental Associates; DK = Denmark (Scandinavia).

CI: 1.5-3.3); $\mathrm{p}<0.001$ ]. Additionally, lesions light in color were more common in pediatric than in adult patients. Considering color-luster combinations, $10 \%$ were chalkylight, $47 \%$ were shiny-dark, and $42 \%$ were mixtures. Lesions that were a combination of chalky and light were more commonly found among pediatric than among adult patients $[22 \%(152 / 693)$ vs. $6 \%(122 / 1,910)$; adjusted for clustering OR = 2.9 (95\% CI: 1.9-4.4); $\mathrm{p}<0.001$ ].

\section{Diagnostic Aids}

Dental explorers and air drying were used in diagnosing the vast majority of lesions - at 91 and $94 \%$, respectively - while magnification and radiographs were each used in diagnosing less than half of the lesions overall (table 2). Use of magnification ranged from $9 \%$ in DK to $85 \%$ in $\mathrm{MN}$; use of radiographs ranged from $30 \%$ in Southeast USA (AL/MS and FL/GA) to $64 \%$ in MN. 
Table 2. Tooth, lesion, diagnostic and treatment characteristics by region*

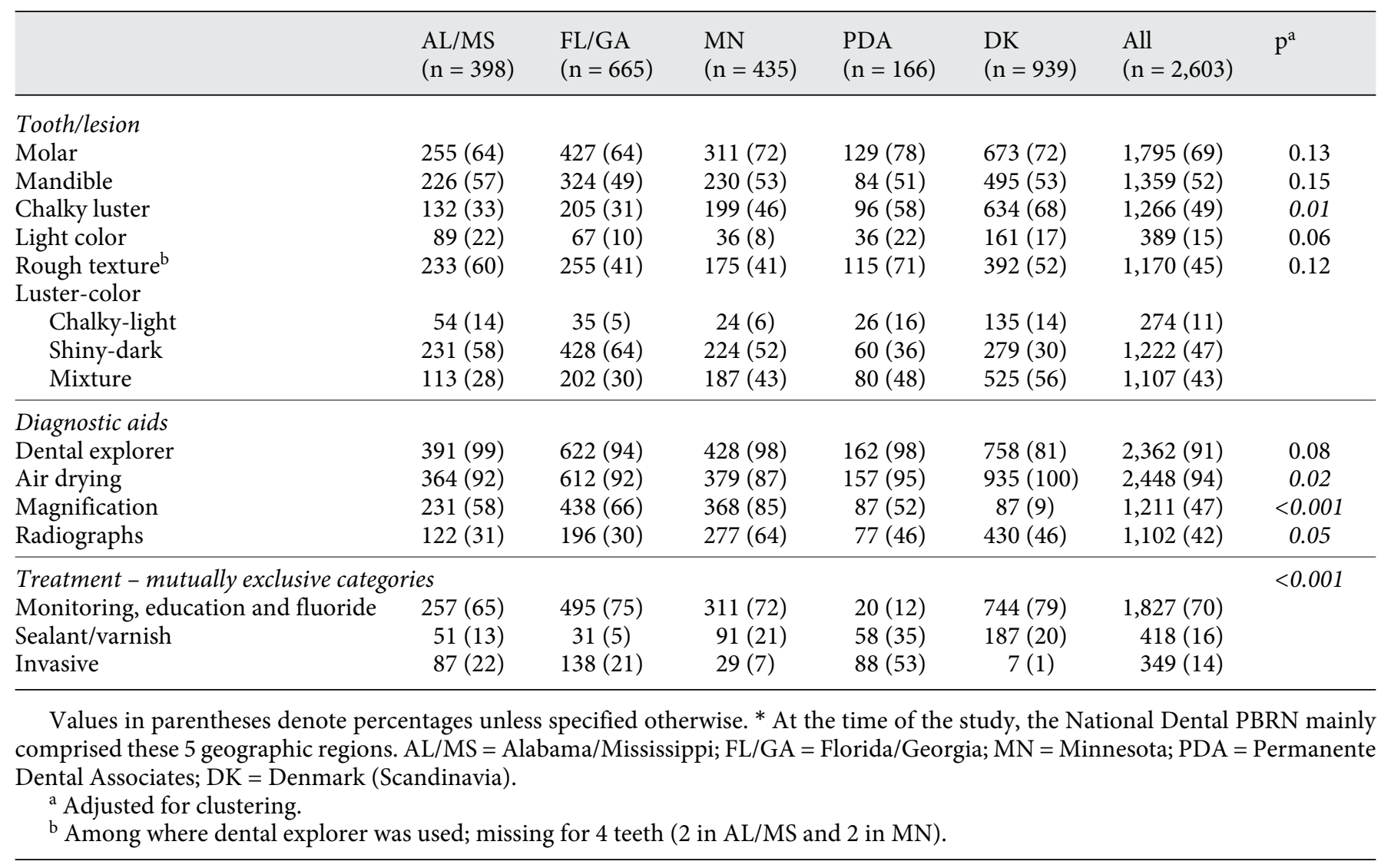

Table 3. Materials used and findings among lesions treated invasively, by region*

\begin{tabular}{|c|c|c|c|c|c|c|}
\hline & $\begin{array}{l}\mathrm{AL} / \mathrm{MS} \\
(\mathrm{n}=398)\end{array}$ & $\begin{array}{l}\text { FL/GA } \\
(\mathrm{n}=665)\end{array}$ & $\begin{array}{l}\mathrm{MN} \\
(\mathrm{n}=435)\end{array}$ & $\begin{array}{l}\text { PDA } \\
(\mathrm{n}=166)\end{array}$ & $\begin{array}{l}\text { DK } \\
(n=939)\end{array}$ & $\begin{array}{l}\text { All } \\
(\mathrm{n}=2,603)\end{array}$ \\
\hline \multicolumn{7}{|l|}{ Findings } \\
\hline No lesions & $5(7)$ & $23(17)$ & $3(18)$ & $26(30)$ & $0(0)$ & $57(18)$ \\
\hline Inactive lesions & $1(1)$ & $12(9)$ & $0(0)$ & $21(24)$ & $0(0)$ & $34(10)$ \\
\hline Active lesions & $70(92)$ & $103(75)$ & $14(82)$ & $21(47)$ & $7(100)$ & $235(72)$ \\
\hline \multicolumn{7}{|l|}{ Among active lesions } \\
\hline Enamel & $6(9)$ & $39(38)$ & $1(7)$ & $17(42)$ & $6(86)$ & $69(29)$ \\
\hline Dentin & $64(91)$ & $64(62)$ & $13(93)$ & $24(59)$ & $1(14)$ & $166(71)$ \\
\hline Missing information & 11 & 0 & 12 & 0 & 0 & 23 \\
\hline \multicolumn{7}{|l|}{ Material used } \\
\hline Amalgam & $7(9)$ & $7(5)$ & $8(47)$ & $8(9)$ & $0(0)$ & $30(9)$ \\
\hline Composite & $72(89)$ & $122(91)$ & $6(35)$ & $32(38)$ & $7(100)$ & $239(74)$ \\
\hline Glass ionomer & $2(3)$ & $1(1)$ & $0(0)$ & $10(12)$ & $0(0)$ & $13(4)$ \\
\hline Other & $0(0)$ & $4(3)$ & $3(18)$ & $35(41)$ & $0(0)$ & $42(13)$ \\
\hline Missing information & 6 & 4 & 12 & 3 & 0 & 25 \\
\hline
\end{tabular}

Values in parentheses denote percentages unless specified otherwise. Column totals not summing up to the total treated invasively are due to missing data on findings and/or materials used. In AL/MS, 11 lesions treated invasively had missing data on findings, and 12 in $\mathrm{MN}$. For materials used, 6 lesions had missing information in AL/MS, 4 in FL/GA, 12 in MN and 3 in PDA. * At the time of the study, the National Dental PBRN mainly comprised these 5 geographic regions. AL/MS = Alabama/Mississippi; FL/GA = Florida/Georgia; $\mathrm{MN}=\mathrm{Minnesota}$; $\mathrm{PDA}=$ Permanente Dental Associates; DK = Denmark (Scandinavia). 


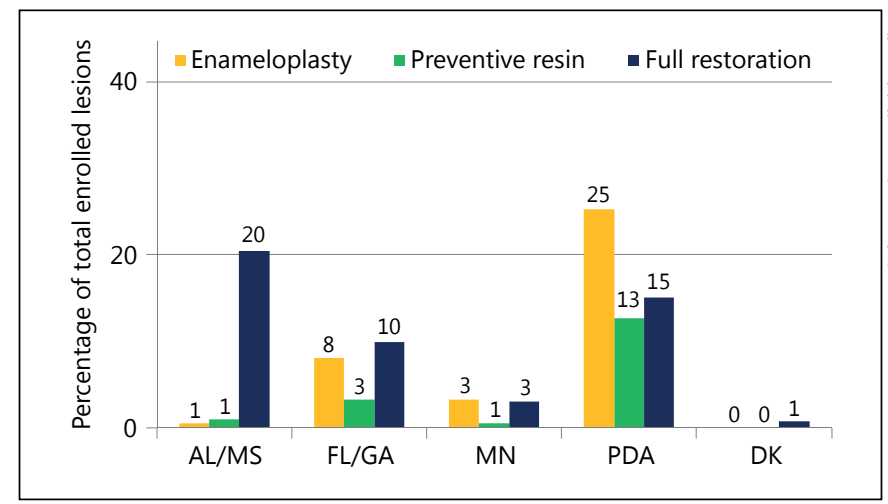

Fig. 1. Type of invasive treatment by region.

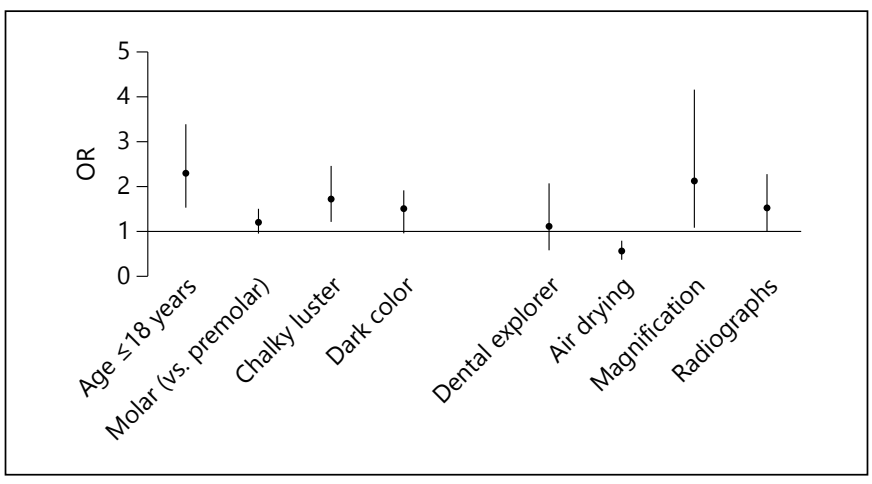

Fig. 2. Patient, tooth and lesion characteristics and diagnostic aids associated with receipt of invasive treatment for QOC $(n=326)$.

\section{Use of Diagnostic Aids}

After accounting for clustering within practice, no patient, tooth or lesion characteristic was associated with use of dental explorer. No patient, tooth or lesion characteristic was associated with use of air drying, but air drying was used more in pediatric than in general practices. Chalky luster was associated with a small increase in use of radiographs (OR $=1.2 ; 95 \% \mathrm{CI}: 1.0-1.4 ; \mathrm{p}=0.02$; full model). A model including all regions could not be fit for magnification because of cluster size, number and lack of variation within the cluster. Excluding DK, a model was fit; pediatric patient $(\mathrm{OR}=0.8 ; 95 \% \mathrm{CI}: 0.7-1.0 ; \mathrm{p}=0.04)$ and light color $(\mathrm{OR}=0.8 ; 95 \% \mathrm{CI}: 0.7-1.0 ; \mathrm{p}=0.04)$ were each associated with a small reduction in use of magnification.

\section{Treatments}

Overall, $70 \%$ of lesions were treated solely with monitoring, education or fluoride, $16 \%$ with sealant or varnish, and $14 \%$ with some type of invasive treatment (table 2). Enameloplasty was used for 112 of the 349 lesions treated with an invasive procedure, preventive resin restorations for 49 lesions, and full restoration for 192 lesions. Treatment method varied considerably across regions, particularly invasive treatment, which varied from $1 \%$ in DK to $53 \%$ in PDA. Type of invasive restoration procedure also varied across regions (fig. 1): use of enameloplasty ranged from $0 \%$ in DK to $25 \%$ in PDA, use of preventive resin restoration from $0 \%$ in $\mathrm{DK}$ to $13 \%$ in $\mathrm{PDA}$, and use of full restorations from $1 \%$ in $\mathrm{DK}$ to $20 \%$ in $\mathrm{AL} / \mathrm{MS}$.

\section{Clinical Findings/Materials Used}

There were data on clinical findings for 326 of the 349 lesions treated invasively (table 3 ). No caries was observed in $18 \%$ of these lesions, inactive caries in $10 \%$, and active caries in $72 \%$. This differed by type of invasive treatment: among those treated by enameloplasty, $28 \%$ $(28 / 101)$ had active caries; $66 \%(29 / 44)$ had preventive resin restoration, and $98 \%(178 / 181)$ had full restoration. As with clinical findings, materials used for restoration depended largely on type of treatment and findings. As can be seen in table 3, composite was the restorative material used for treatment of $74 \%$ of the lesions, amalgam for $9 \%$ and glass ionomer for $4 \%$ of the lesions.

\section{Use of Invasive Treatment}

After adjusting for clustering within practice, no practice or practitioner characteristic was associated with type of invasive treatment. In full models, pediatric patient, chalky luster and use of magnification were associated with an increased likelihood of invasive treatment (fig. 2). Removing nonsignificant variables (reduced model) had no discernible effect on findings compared with the full model: no additional variables became significant, the variables significant in the full model remained so, and the magnitude of association was similar. In PDA, in which $25 \%$ of the lesions were treated by enameloplasty, there were no significant predictors, nor were there in the $\mathrm{AL} / \mathrm{MS}$ region. In MN ( $3 \%$ were treated by enameloplasty), however, being a 'pediatric' patient was strongly associated with enameloplasty (OR $=19.5$; 95\% CI: $5.3-$ $71.7 ; \mathrm{p}<0.001)$ and having a chalky luster was strongly associated with not being treated by enameloplasty $(\mathrm{OR}=$ 0.1 ; 95\% CI: 0.01-0.77; $\mathrm{p}=0.03$ ).

\section{Discussion}

Dental care has slowly evolved from a time of restoring all carious lesions, regardless of size, to 'early detection and management' [Bader and Shugars, 2006]. Hamilton 
et al. [2002] studied 223 QOC in a randomized trial comparing air abrasion with monitoring over a 2 -year observation period. Only $16 \%(n=100)$ of the lesions randomized to the monitoring arm progressed into the dentin by the end of the 2-year observation period, showing that conservation of the tooth structure is possible and that operative intervention for QOC is not recommendable.

In Western countries, $40 \%$ of restorations are placed on primary carious lesions - generally smaller lesions which can lead to overtreatment [Browning and Dennison, 1996]. Information gathered on these smaller lesions can lead to cost-effective health care delivery and reduce unnecessary treatment [Browning and Dennison, 1996; Verdonschot et al., 1999]. A recent study on dentin caries activity in early occlusal lesions concluded that sealing of early or shallow occlusal lesions would be more beneficial to the patient than operative treatment [Lehmann et al., 2012]. A pilot study conducted by Miller et al. [1995] opened 8 'potentially' carious tooth surfaces (light or dark brown discoloration or white inside the pit and softness when an explorer was passed over the pit) and found that 5 of the 8 only had a stain and only 3 had carious lesions, but these were limited to the enamel, meaning preventive measures would have been appropriate for all 8 teeth. Another study, conducted by Ekstrand et al. [1997], looked at 100 occlusal surfaces for the purpose of investigating the accuracy of a visual ranked caries scoring system, an electronic caries scoring system, and a radiographic ranked caries scoring system. The authors concluded there was a high correlation between the visual and electronic caries scoring system methods and lesion depth in both enamel and dentin, but they found that caries limited to the enamel could not be detected through radiographic examination.

Another, more recent, study by Ekstrand et al. [2007] tested the accuracy of the ICDAS I and ICDAS II caries detection systems for assessing occlusal carious lesion activity. They concluded that it was possible to predict the lesion depth and assess the activity of these lesions accurately by using visual appearance, location of the lesion, and tactile sensation during probing.

There are some limitations to this study. It investigated diagnosis and treatment as delivered in routine, 'realworld' clinical practice and therefore made no attempt to standardize or calibrate that diagnosis or treatment. Each practice was trained specifically for this study so as to standardize the data collection process, but no effort was made to standardize diagnostic or treatment methods for QOC - indeed, such standardization would not be desirable because an objective of the study was to determine the distribution of the characteristics of these lesions given the diagnostic methods which they normally use in routine practice.

It is interesting to note that as age increased, the number of QOC found on molars decreased. This could be due to the fact that these surfaces may already have had restorations or sealants placed on them at a younger age [Dye and Thornton-Evans, 2010]. Another reason could be that dentists tend to treat occlusal surfaces in older patients less aggressively because, presumably, these 'lesions' have been there and not progressed. The results also illustrate that color of the lesion changed as age increased on both molars and premolars, with opaque-towhite lesions decreasing as age increased, reflecting the natural development of occlusal carious lesions over time. The regression analyses performed also indicate that practitioners did not distinguish between the color-andluster combined categories when making their treatment decisions. The Hamilton study found a strong correlation between fissure color (light brown and dark brown fissures had more caries penetrating the dentin compared with tooth-colored or yellow-orange fissures) and fissure feel (retention at baseline led to the tooth more likely being treated for caries within a 24-month period) [Hamilton et al., 2002]. This information is important when diagnosing and treating QOC in daily clinical practice.

To our knowledge, this is the first study to report the distribution of characteristics of QOC in routine clinical practice. The phenomenon is common (with a prevalence of $>30 \%$ ), and the age of the patient as well as tooth location and characteristics are important factors to be considered when diagnosing these lesions.

\section{Acknowledgements}

This investigation was supported by NIH grants U01-DE-16746, U01-DE-16747 and U19-DE-22516. S.K.M., G.H.G., J.D.B., V.V.G., D.B.R., D.J.P. and V.Q. conceived and designed the study; the National Dental PBRN collaborative group performed the study; E.F. analyzed the data; S.K.M., G.H.G., J.D.B., V.V.G., D.B.R., D.J.P. and V.Q. wrote the paper.

\section{Disclosure Statement}

All authors declare no conflicts of interest. The funders had no role in the study design, data collection and analysis, decision to publish, or preparation of the manuscript. The opinions and assertions contained herein are those of the authors and are not to be construed as necessarily representing the views of the respective organizations or the NIH. 


\section{References}

- Bader JD, Shugars DA: The evidence supporting alternative management strategies for early occlusal caries and suspected occlusal dentinal caries. J Evid Based Dent Pract 2006;6:91100.

Balevi B: The management of suspicious or incipient occlusal caries: a decision tree analysis. Community Dent Oral Epidemiol 2008;36 392-400.

-Basting RT, Serra MC: Occlusal caries: diagnosis and noninvasive treatments. Quintessence Int 1999;30:174-178.

Brown LJ, Wall TP, Lazar V: Trends in total caries experience: permanent and primary teeth. J Am Dent Assoc 2000;131:223-231.

Browning WD, Dennison JB: A survey of failure modes in composite resin restorations. Oper Dent 1996;21:160-166.

$>$ Dye BA, Thornton-Evans G: Trends in oral health by poverty status as measure by Healthy People 2012 objectives. Public Health Rep 2010; 125:817-830.

-Ekstrand KR, Martignon S, Ricketts DJ, Qvist V: Detection and activity assessment of primary coronal caries lesions: a methodologic study. Oper dent 2007;32:225-235.

Ekstrand KR, Ricketts DN, Kidd EA: Reproducibility and accuracy of three methods for assessment of demineralization depth of the occlusal surface: an in vitro examination. Caries Res 1997;31:224-231

Frencken JE, Peters MC, Manton DJ, Leal SC, Gordan VV, Eden E: Minimal intervention dentistry for managing dental caries - a review: report of a FCI task group. Int Dent J 2012;62:223-243.

-Gilbert GH, William OD, Rindal DB, Pihlstrom DJ, Benjamin PL, Wallace MC, DPBRN Collaborative Group: The creation and development of the Dental Practice-Based Research Network. J Am Dent Assoc 2008;139:74-81.

Groeneveld A, van Eck AA, Backer Dirks O: Fluoride in caries prevention: is the effect pre- or post-eruptive? J Dent Res 1990;69(spec No): $751-755$.

Hamilton JC, Dennison JB, Stoffers KW, Gregory WA, Welch KB: Early treatment of incipient carious lesions: a two-year clinical evaluation. J Am Dent Assoc 2002;133:1643-1651.
Hamilton JC, Dennison JB, Stoffers KW, Welch $\mathrm{KB}$ : A clinical evaluation of air abrasion treatment of questionable carious lesions: a 12-month report. J Am Dent Assoc 2001;132. 762-769.

Ismail AI, Hasson H, Sohn W: Dental caries in the second millennium. J Dent Educ 2001;65: 953-959.

Kaste L, Selwitz R, Oldakowski R, Brunelle JA, Winn DA, Brown LJ: Coronal caries in the primary and permanent dentition of children and adolescents 1-17 years of age: United States, 1988-1991. J Dent Res 1996;75(spec No):631-641.

Ketley CE, Holt RD: Visual and radiographic diagnosis of occlusal caries in first permanent molars and in second primary molars. $\mathrm{Br}$ Dent J 1993;174:364-370.

Kidd EAM, Nyvad B: Caries control for the individual patient; in Fejerskov O, Kidd EAM (eds): Dental Caries: The Disease and Its Clinical Management. London, Blackwell Munksgaard, 2003, pp 303-312.

Kidd EAM, Ricketts DNJ, Pitts NB: Occlusal caries diagnosis: a changing challenge for clinician and epidemiologists. J Dent 1993;21: 323-331.

Lehmann M, Veitz-Keenan A, Matthews AG, Vena D, Grill A, Craig RG, Curro FA, Thompson VA: Dentin caries activity in early occlusal lesions selected to receive operative treatment: findings from the Practitioners Engaged in Applied Research and Learning (PEARL) Network. J Am Dent Assoc 2012; 143:377-385.

Lussi A: Comparison of different methods for the diagnosis of fissure caries without cavitation. Caries Res 1993;27:409-416.

Makhija SK, Gilbert GH, Funkhouser EM, Bader JD, Gordan VV, Rindal DB, Bauer M, Pihlstrom DJ, Qvist V, National Dental PBRN Collaborative Group: The prevalence of questionable occlusal caries: findings from the Dental Practice-Based Research Network. J Am Dent Assoc 2012;143:1343-1350.
Makhija SK, Gilbert GH, Rindal DB, Benjamin PL, Richman JS, Pihlstrom DJ, DBPRN Collaborative Group: Dentists in practice-based research networks have much in common with dentists at large: evidence from the Dental PBRN. Gen Dent 2009;57:270-275.

Meiers J, Jensen M: Management of the questionable carious fissure: invasive vs. noninvasive techniques. J Am Dent Assoc 1984;108:64-68.

Miller PA, Ismail AI, MacInnis WA: Restorative management of carious pits and fissures: a new approach (abstract). J Dent Res 1995;74:248.

NHANES III: Third National Health and Nutrition Examination Survey, 1988-1994. National Center for Health Statistics, Centers for Disease Control and Prevention, 1996.

Ouellet A, Hondrum SO, Pietz DM: Detection of occlusal carious lesions. Gen Dent 2002;50: 346-350.

Pine CM, Bosch JJ: Dynamics of and diagnostic methods for detecting small carious lesions. Caries Res 1996;30:381-388.

Pitts NB: Diagnostic tools and measurements: impact on appropriate care. Community Dent Oral Epidemiol 1997;25:24-35.

Pitts NB: Are we ready to move from operative to non-operative/preventive treatment of dental caries in clinical practice? Caries Res 2004;38: 294-304

-Sawle RF, Andlaw RJ: Has occlusal caries become more difficult to diagnose? Br Dent J 1988; 164:209-211.

Verdonschot EH, Angmar-Månsson B, ten Bosch JJ, Deery CH, Huysman MC, Pitts NB, Waller $\mathrm{E}$ : Developments in caries diagnosis and their relationship to treatment decisions and quality of care. ORCA Saturday Afternoon Symposium 1997. Caries Res 1999;33:32-40.

Weerheijm KL, de Soet JJ, de Graaff J, van Amerongen WE: Occlusal hidden caries: a bacteriological profile. ASDC J Dent Child 1990;57: 428-432.

White JM, Eakle WS: Rationale and treatment approach in minimally invasive dentistry. J Am Dent Assoc 2000;131(suppl):13S-19S.

-Winn F, Brunelle J, Selwitz R, Kaste LM, Oldakowski RJ, Kingman A, Brown LJ: Coronal and root caries in the dentition of adults in the United States, 1988-1991. J Dent Res 1996; 75(spec No):642-651. 